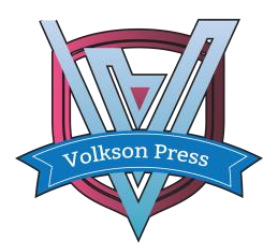

Contents List available at VOLKSON PRESS

Mechanical and Control Engineering (MCE)

DOI : http://doi.org/10.26480/wsmce.01.2017.137.139

ISBN: 978-1-948012-06-5

\title{
STRAIN ANALYSIS OF CRACKED SHAFT BASED ON ELECTRIC MEASUREMENT THEORY
}

Jiao Bolong*, Zhong Zhixian, Wang Jiayuan and Liu Yixin

College of Mechanical and Control Engineering, Guilin University of Technology, Guilin, China
*Corresponding Author Email: jiaokeke@foxmail.com

This is an open access article distributed under the Creative Commons Attribution License, which permits unrestricted use, distribution, and reproduction in any medium, provided the original work is properly cited

\section{ARTICLE DETAILS}

\section{Article History:}

Received 02 october 2017 Accepted 06 october 2017 Available online 11 november 2017

Keywords

Crack, Strain, Electric measurement

\section{ABSTRACT}

The electrical measurement method is adopted. The cracked shaft is regarded as a beam. In case of static force and the cracked shaft rotating 360 degrees, strain at a point near the crack is studied. The effect of crack on the strain of shaft near the crack was discussed. It is found that the surface of the shaft which is in the radial direction of the crack will produce more strain, which has a great significance for the study about the identification of cracks.

\section{FOREWORD}

As we all know, because of varying load, defects of the rotor shaft which is formed in the process of manufacturing and machining, or errors in assembling can generate stress concentration by alternating mechanical stress and thermal stress. And these stress concentrations may develop into fatigue cracks very fast. If these fatigue cracks are not found in time, due to the effect of alternating loads, they will expand, mutate and cause catastrophic fracture accidents [1-3].

So far, many domestic and foreign scholars have studied cracked shaft and cracked rotor [4]. Most studies are about vibration analysis and crack identification, but the key is the treatment of crack. Based on local compliance, Irwin analyzes stress concentrations caused by load and crack [5]. In addition, Kirmsher and Thomsom are the earliest researcher who use the similar gap to simulate the local defects of beams $[6,7]$.

Papadopoulos and Dimarogonas derived the $6 \times 6$ crack local compliance matrix by fracture mechanics [8]. In this paper, the strain of cracked shaft subjected to static load is analyzed and its influence is discussed.

\section{ELECTRIC MEASUREMENT THEORY}

Based on Wheatstone bridge, strain gauge is affixed to the surface of the device which is tested [9]. When the device under test is distorting, the strain gauge will have the same deformation like the device under test. And the resistance of strain gauge will change, therefore the output voltage also changes. As shown in Figure 1, four strain gauges are bridge legs (depending on the type of bridge, a fixed resistance or strain gauge is connected).

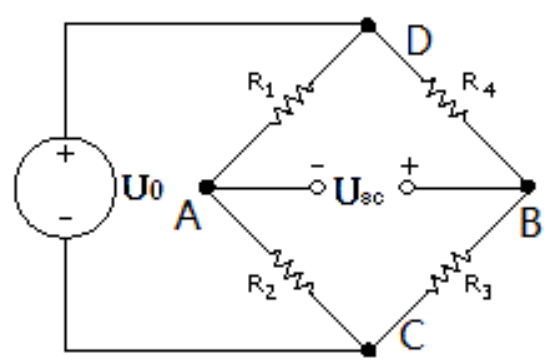

Figure 1: Wheastone bridge circuit
DC is the input terminal (voltage $\left.\mathrm{U}_{0}\right)$ and $A B$ is the output $\left(\mathrm{U}_{\mathrm{sc}}\right)$,

$$
\begin{gathered}
U_{s c}=U_{B C}-U_{A C}=I_{2} R_{3}-I_{1} R_{2}=\frac{U_{0}}{R_{3}+R_{4}} R_{3}-\frac{U_{0}}{R_{1}+R_{2}} R_{2} \\
=\frac{R_{1} R_{3}-R_{2} R_{4}}{\left(R_{1}+R_{2}\right)\left(R_{3}+R_{4}\right)} U_{0}
\end{gathered}
$$

When $R_{1} R_{3}-R_{2} R_{4}=0$, the output voltage is $U_{s c}=0$, and the bridge is in equilibrium state. When the strain plate is deformed, four bridge arms are connected to the strain gauge, and the four bridge arms change simultaneously. The initial state is $\mathrm{R}_{1}=\mathrm{R}_{2}=\mathrm{R}_{3}=\mathrm{R}_{4}$, and the output voltage is as follows

$$
\begin{gathered}
U_{s c}=\frac{U_{0}}{4}\left(\frac{\Delta R_{1}}{R_{1}}-\frac{\Delta R_{2}}{R_{2}}+\frac{\Delta R_{3}}{R_{3}}-\frac{\Delta R_{4}}{R_{4}}\right) \\
\Delta \mathrm{R} / \mathrm{R}=\mathrm{K} \varepsilon \\
U_{s c}=\frac{U_{0} K}{4}\left(\varepsilon_{1}-\varepsilon_{2}+\varepsilon_{3}-\varepsilon_{4}\right)
\end{gathered}
$$

The strain is obtained according to the voltage variation.

\section{THE EXPERIMENT DESCRIBED AND THEORETICAL CALCULATION}

The shaft material is 45 steel. Length, diameter and materials of the two shafts under test are the same. By laser cutting, one of the shaft is processed a incision which is length of $5 \mathrm{~mm}$ to simulate the crack. The diameter of shaft is $10 \mathrm{~mm}$, and it is fixed to a index plate. AB is regarded as a cantilever. A side is applied a constant load P (given a total mass of $800 \mathrm{~g}$ weight). The length of shaft $\mathrm{L}_{1}$ is $500 \mathrm{~mm}$, and the distance between crack $C$ and $A$ is $L_{2}$ which is $222 \mathrm{~mm}$. $L_{3}$, distance between measurement point $\mathrm{E}$ and $\mathrm{A}$, is $212 \mathrm{~mm}$. 4 strain gauges are affixed at every 90 degrees. The structure of testbed is shown in Figure 2. The photo of testbed is shown in Figure 3. Crack and affixing method of strain gauge is in Figure 4. 


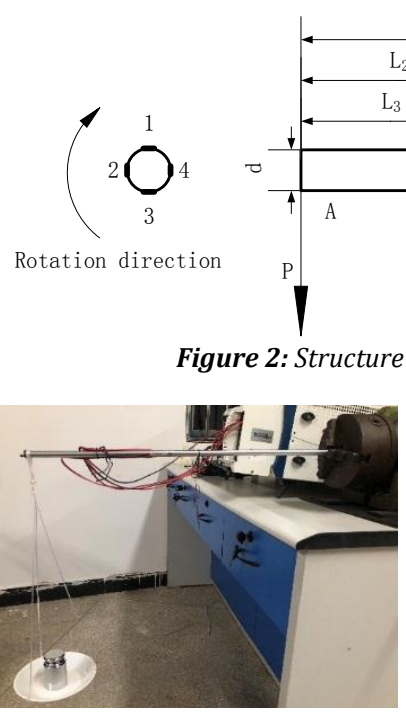

Figure 3: Test bench photos

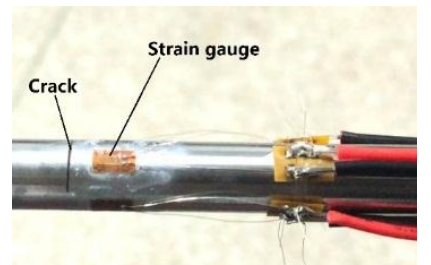

Figure 4: Crack and strain gauge

Strain gauges are $120 \Omega$, base size: $6.6 \times 3.2 \mathrm{~mm}$, wire mesh size: $3 \times 2.3 \mathrm{~mm}$, sensitivity coefficient 2 . The bridge adopts $1 / 4$ bridge I type, as shown in figure Figure $5, R_{L}$ is wire resistance, and $R_{4}$ is strain gauge resistor,

$\mathrm{R}_{\mathrm{L}}$

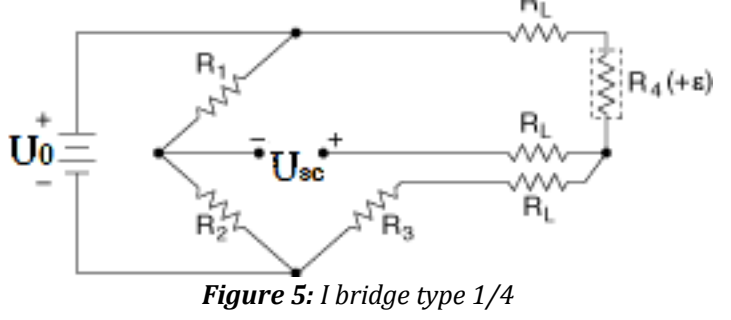

The normal stress produced by the bending moment on the point cell of the measuring point $\mathrm{E}$ is delta $\mathrm{x}$, as shown in figure Figure 6.

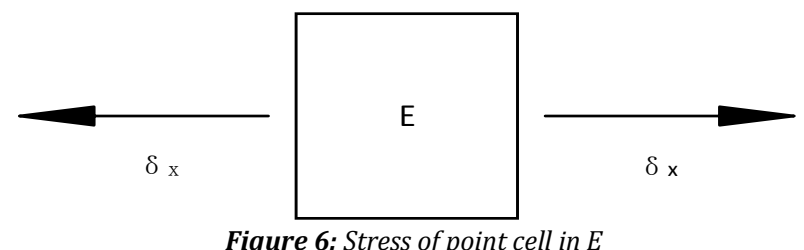

Figure 6: Stress of point cell in $E$

According to the theory of material mechanics, Strain value is : [10].

$$
\varepsilon=\frac{M y}{E I}
$$

In equation:

$\varepsilon-$ - Strain (Micro strain 106)

$\mathrm{M}-$ - bending moment $\left(\mathrm{P} \times \mathrm{L}_{3}\right)$

layer(m)

$\mathrm{y}-$-Distance between strain measuring point and the neutral

E-_Elastic modulus of materials $\left(2 \times 10^{9} \mathrm{~Pa}\right)$

I--Moment of inertia of cross section ( circular: $\frac{\pi d^{4}}{64}$ )

After the graduated plate turning the angle $\theta$, the distance between the strain gauges $1,2,3,4$ and the neutral layer is $d \cos \theta, d \sin \theta,-d \cos \theta,-$ $\mathrm{d} \sin \theta$ respectively.

Comparison of strain between data of no crack shaft and crack shaft is shown in Figure 7, Figure 8, Figure 9, Figure 10 respectively.

No.1

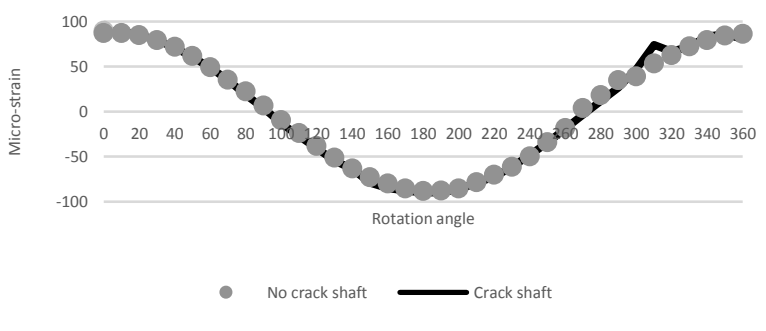

Figure 7: The strain of No.1

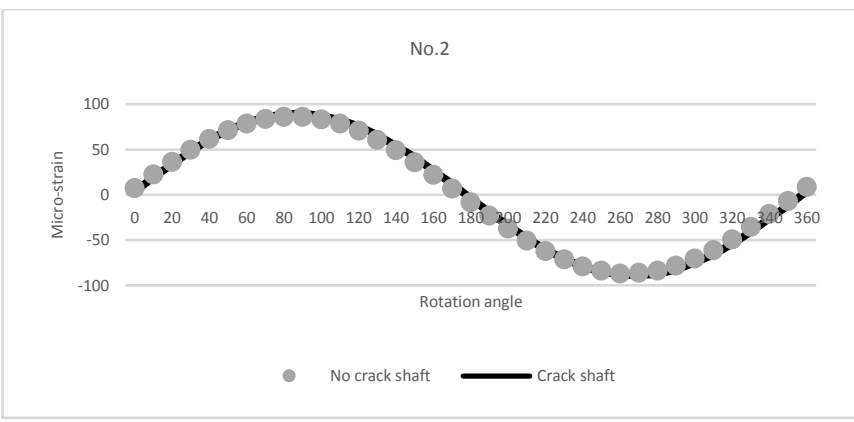

Figure 8: The strain of No.2

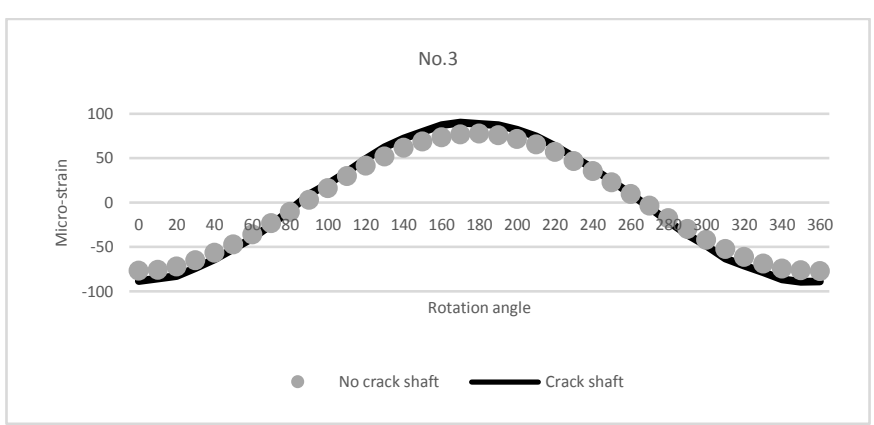

Figure 9: The strain of No.3

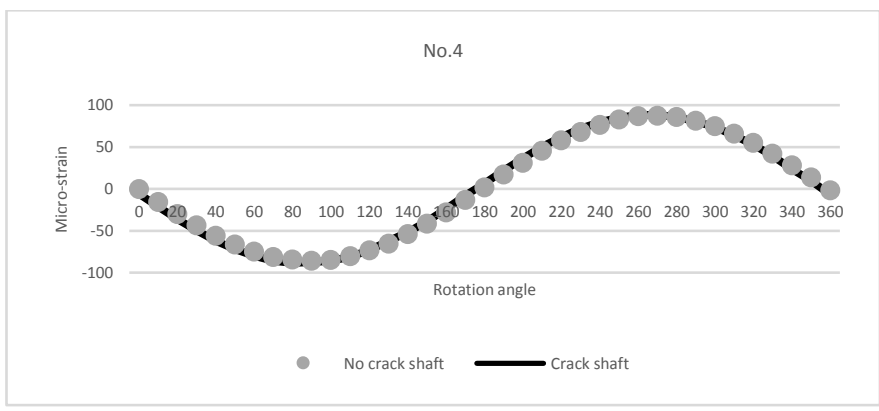

Figure 10: The strain of No.4

The difference between the variation of strain in the position1,2,4 of the crack shaft and the no crack one is very small. After rotating 360 degrees, in the No.3 position, the variation of strain all increases. The maximum variation of strain occurs when the direction of load coincides with the direction of the measuring point, and compared with no crack one, the variation of strain of crack shaft increases by about $13 \%$. When the direction of the load is perpendicular to the direction of the measuring point, the difference does not come out, because deformation of measuring point is very small.

\section{CONCLUSIONS}

The opening and closing of the crack cannot be measured, and the amount of deformation inside the shaft through the experiment. However, the strain at the surface of the shaft near the crack can be measured in order to research the effect of the crack on strain of the shaft. The crack on the shaft reduces the local stiffness of the cracked shaft and creates stress concentrations. The surface of the shaft which is in the radial direction of the crack will produce more strain, when subjected to the load, the strain at the measuring point around the crack is almost as same as the strain at the no crack shaft.

In this paper, the strain of the cracked shaft under static load is mainly 
analyzed. Expanding to a periodic variable load, the crack will be expanded due to the fatigue. The size of the strain change in the test point can determine whether there is any crack, and can know the direction of crack growth, as well as the location of cracks. This has a great significance for the study of the identification of cracks.

\section{REFERENCES}

[1] Jie, H., Ruilin, Z. 1997. Rotating machinery failure mechanism and diagnostic techniques [M]. Beijing: Mechanical Industry Press Du.

[2] Jin, C. 1999. Mechanical Equipment Vibration Monitoring and Fault Diagnosis [M], Shanghai: Shanghai Jiao Tong University Press.

[3] Guang, M. 2002. Review and Prospect of Rotor Dynamics Research. Journal of Vibration Engineering [J], 15 (1), 1-9.

[4] Dimarogonas, A.D. 1996. Vibration of cracked structures: a state of the art review [J]. Engneering Fracture Mechanics, 55 (5), 831-875.
[5] Irwin, G.R. 1957. Analysis of stresses and strains near the end of a crack traversing a plate [J]. Journal of Applied Mechanics, 24, 361-364.

[6] Kirmsher, P.G. 1944.The effect of discontinuities on the natural frequency of beams. Proc [J]. American society of testing and materials, 44, 897-904.

[7] Thomson, W.J. 1943. vibration of slender bars with discontinuities in stiffness [J]. Journal of Applied Mechanices, 17, 203-207.

[8] Papadopoulos, C.A., Dimarogous. 1987. Coupled longitudinal and bending vibrations of a rotating shaft with an open crack [J]. Journal of Sound and Vibration, 117 (1), 81-83.

[9] Fuyan, Y., Wenrui, W. 2014. High temperature / low temperature resistance strain gauge and its application [M], Beijing: National Defense Industry Press.

[10] Qinshan, F., Yajun, Y. 2004. Mechanics of Materials [M], Beijing: Tsinghua University Press 